\title{
Pressure Estimation and Pressure Control of Hydraulic Control Unit in Electric-Wheel Vehicle
}

\author{
Zhao Xiangyang, ${ }^{1}$ Xu Wen-bo, ${ }^{1}$ and Gang Liu $\mathbb{1}^{2}$ \\ ${ }^{1}$ Department of Automotive Engineering, Henan Institute of Technology, Xinxiang 453000, China \\ ${ }^{2}$ State Key Laboratory of Automotive Simulation and Control, Jilin University, Changchun 130022, China \\ Correspondence should be addressed to Gang Liu; gliu14@mails.jlu.edu.cn
}

Received 1 February 2020; Revised 5 May 2020; Accepted 1 June 2020; Published 14 July 2020

Academic Editor: Pietro Bia

Copyright (C) 2020 Zhao Xiangyang et al. This is an open access article distributed under the Creative Commons Attribution License, which permits unrestricted use, distribution, and reproduction in any medium, provided the original work is properly cited.

\begin{abstract}
In order to improve the braking performance and safety performance of electric vehicles driven by a hub motor, the cylinder pressure estimation and pressure control of its hydraulic braking system are studied. In this paper, a mathematical model is established for the solenoid valve, a key component of the hydraulic actuator, and the hydraulic and electrical characteristics of the solenoid valve are studied. A state equation is established for the solenoid valve, and the square root volume Kalman filter (SRCKF) algorithm is used to estimate the solenoid valve spool position. The brake fluid flow and brake wheel cylinder pressure are calculated based on the spool position. Finally, a solenoid valve spool position control algorithm based on sliding mode variable structure algorithm is designed, and the brake pressure in the brake wheel cylinder is controlled by adjusting the spool position. Matlab/Simulink-AMESim software simulation and hardware-in-the-loop were used to verify the algorithm. Simulation results show that the brake cylinder pressure can be estimated accurately, and the pressure control algorithm can accurately follow the control target value.
\end{abstract}

\section{Introduction}

Electric vehicles driven by in-wheel motors are highly competitive in the market. An important method to improve the energy utilization rate of electric vehicles is braking energy recovery technology. This technology has always been a hot research area for electric vehicles. While studying the braking energy regenerative technology, the research team designed a new type of hydraulic control unit. Based on the HCU, a series of regenerative braking energy coordinated control research is carried out [1-3]. During the research, it is found that accurate estimation of brake wheel cylinder pressure and pressure linear control are the basis of electric vehicle regenerative braking and ABS control [4-7].

The target wheel cylinder pressure is calculated by the ABS control algorithm. Based on the target wheel cylinder pressure, the estimated value of the current pressure of the wheel cylinder, and the current solenoid valve working condition, the solenoid valve control command is calculated by the pressure control algorithm. The current actual pressure of the wheel cylinder and the target pressure are monitored in real time. The control command and working status of the solenoid valve are constantly adjusted by the pressure control algorithm so that the actual pressure of the wheel cylinder reaches the target pressure as soon as possible.

$\mathrm{Qu}$ introduced the pressure control method based on program logic (if-else) [8]. The inlet and outlet valves of hydraulic control unit (HCU) are adjusted to achieve the control of the wheel cylinder pressure. The use of program logic (if-else) method will cause the actual pressure of the wheel cylinder to fluctuate greatly, and the highly reliable PID control algorithm $[9,10]$ is used to design the wheel cylinder pressure controller.

Due to the increasingly higher requirements for control accuracy and speed of the wheel cylinder pressure control system, the PID algorithm has gradually failed to meet the demand. Aiming at the various defects of PID control algorithms, such as poor real-time control system, poor robustness, easy to generate oscillations in the integration link, susceptibility to external disturbances, and sensitivity to 
changes in system parameters, various advanced and effective control theories [11-13] were used to design the wheel cylinder pressure controller.

The hydraulic pressure control unit (HCU) is the core unit of the hydraulic pressure control system. The solenoid valve is one of the main devices. The hydraulic pressure control of the wheel cylinder is closely related to the solenoid valve. At present, commonly used solenoid valves include on-off valves, high-speed on-off valves, and linear solenoid valves. Since the on-off valve only has two states of open and closed, it is very difficult to achieve continuous flow control. In [14], it was found that the wheel cylinder pressure fluctuated greatly during the braking process of ABS.

The high-speed on-off valve has the same working principle as the traditional on-off valve. The on-off of the brake fluid is controlled by switching between the on and off states of the high-speed solenoid valve. The difference is that the operating frequency of the high-speed on-off valve is higher. In [15], the method of using PWM signal to control the solenoid valve is proposed, and it is verified in experiment that the brake fluid flow is proportional to the PWM signal. In [16], by effectively adjusting the PWM signal, the brake fluid flow is controlled approximately linearly.

The proportional valve can continuously control the brake fluid flow. However, the cost of the proportional valve is relatively high, and it is not realistic to apply it to the automobile brake system. In [17], the pressure of the four wheel cylinders can be smoothly controlled by the solenoid valve. In the ABS control system, the proportional valve can ensure that the wheel cylinder pressure accurately follows the target pressure value.

After analysis of references, in order to improve the braking performance and safety performance of the wheel motor-driven electric vehicle, a composite braking system was designed. In compound brake systems, high-speed on-off valves are used to control the brake fluid flow. The mathematical model of the high-speed on-off valve was established, the hydraulic characteristics and the electrical characteristics of the high-speed on-off valve were studied. The state equation of the high-speed switching valve is established, and the square root volume Kalman filter (SRCKF) algorithm $[18,19]$ is used to estimate the position of the solenoid valve spool. The current brake wheel cylinder pressure is calculated based on the spool position. According to the PV characteristics, a wheel cylinder pressure control algorithm based on the sliding mode variable structure algorithm is designed.

This paper is structured as follows: in Section 2, the HCU structure and working principle of the regenerative braking system designed by the project team are briefly introduced, and the method of pressure increase is also introduced; in Section 3, the dynamic model of the HCU is derived, and the electromagnetic characteristics and electrical characteristics of the solenoid valve required for pressure control are analyzed; in Section 4, the SRCKF-based estimation algorithm of spool position is designed, and the wheel cylinder pressure control algorithm is derived based on the spool position data; in Section 5, the method proposed in this paper is verified by software cosimulation; in Section 6, experiments are conducted to prove the performance of the entire control system; and conclusions are made in Section 7.

\section{HCU Function Introduction}

As shown in Figure 1, the HCU mainly includes two parts: the solenoid valve and the high-pressure accumulator. The high-pressure accumulator has two main functions. First, in the pure motor braking mode, the brake fluid generated by the driver pressing the brake pedal is temporarily stored in the high-pressure accumulator. Second, when relying on pure motor braking, the braking force is insufficient, and the brake fluid in the accumulator can quickly replenish the braking pressure. The solenoid valve is responsible for adjusting the brake pressure in the brake wheel cylinder, which is the basic brake torque of the electric vehicle. Hydraulic braking torque is mainly used in combination with motor braking torque to achieve the vehicle's deceleration function. The purpose of this paper is to design a method of controlling the position of the solenoid valve spool. The valve spool is used to adjust the increase rate of the brake fluid, and when the brake pressure reaches the target value, the solenoid valve is closed. With this linear pressure increase approach which is based on valve spool displacement regulation, accurate wheel cylinder pressure (WCP) control can be achieved.

\section{Modeling of the Solenoid Valve}

The structure of the solenoid valve can be referred from Dr. Fan's thesis [20]. When the current does not flow through the solenoid valve coil, the valve spool is affected by the spring force. At this time, the solenoid valve spool is fully opened. The brake fluid flows into the brake wheel cylinder through the solenoid valve and generates braking force. In contrast, when a current flows through the coil, the generated electromagnetic force overcomes the spring force. The opening of the solenoid valve core is gradually reduced, which will reduce the flow of brake fluid into the brake wheel cylinder and reduce the wheel cylinder pressure.

During braking, the valve spool is mainly subjected to spring force, friction force between push rod and pipe wall, electromagnetic force, and hydraulic power of brake fluid. The structure of the on-off solenoid valve is shown in Figure 2. 1 in the figure represents the working air gap. 2 represents the spool. 3 represents the valve seat. 4 in the figure represents the coil. 5 represents the outlet of valve. 6 represents the inlet of valve. 7 represents the secondary air gap.

The force analysis diagram of the solenoid valve is shown in Figure 3. The force model of the spool can be expressed as follows:

$$
m \ddot{z}_{\mathrm{ev}}=F_{m}-F_{s}-F_{k}-C u \cdot \dot{z}_{\mathrm{ev}},
$$

where $z_{\mathrm{ev}}$ denotes the spool position and its range from $0 \mathrm{~mm}$ to $0.22 \mathrm{~mm}, m$ denotes the total mass of the spool, $F_{m}$ denotes the electromagnet force acting on the spool, $F_{s}$ denotes the flow force acting on the spool, $F_{k}$ denotes the force produced by return spring, and $\mathrm{Cu}$ is the coefficient of viscous friction.

The model of electromagnetic force $F_{k}$ can be expressed 

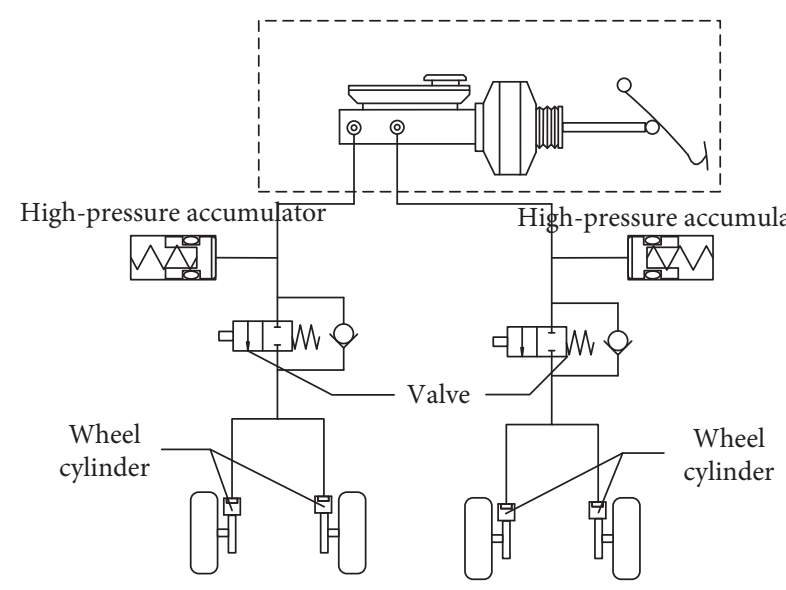

FIGURE 1: Architecture of proposed hydraulic control unit.

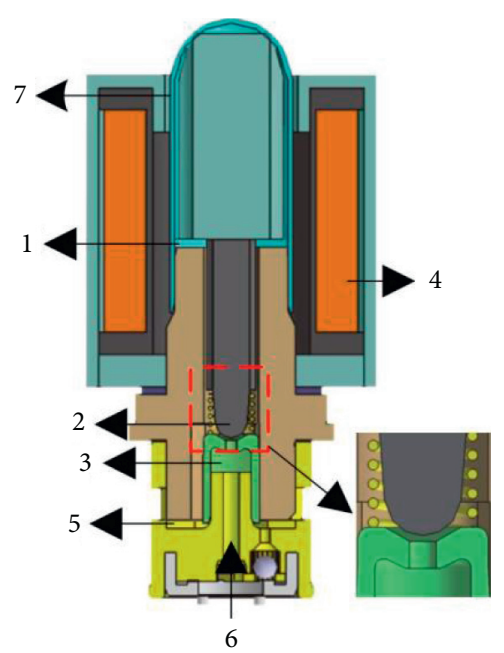

Figure 2: The structure of the on-off solenoid valve.

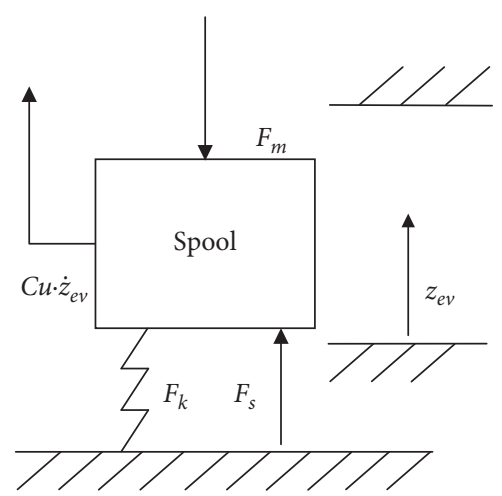

FIgURE 3: Force analysis diagram of valve.

$$
F_{k}=F_{0}+K_{k} \cdot z_{\text {ev }}
$$

where $F_{0}$ denotes the preload force and $K_{k}$ denotes the stiffness coefficient of the return spring.
3.1. Electromagnetic Force Generated by the Solenoid Valve. According to Maxwell' stress theory, the electromagnetic force acting on the spool can be expressed as

$$
F_{m}=\frac{\psi\left(i, z_{\mathrm{ev}}\right)^{2}}{2 \mu_{0} S_{0}}
$$

where $S_{0}$ denotes the area of the magnetic pole, $\mu_{0}$ denotes the permeability coefficient, and $\psi\left(i, z_{\text {ev }}\right)$ denotes the flux linkage through the main air gap, which is the model of coil current $i$ and spool position $z_{\mathrm{ev}}$ :

$$
\psi=\frac{i \cdot n}{R_{m 1}+R_{m 2}}
$$

where $n$ denotes the number of coil turns, $R_{m 1}$ denotes the magnetoresistance parameters of the working air gap, and $R_{m 2}$ denotes the magnetoresistance parameters of secondary air gap. The mathematical models of $R_{m 1}$ and $R_{m 2}$ can be expressed as follows:

$$
\begin{aligned}
& R_{m 1}=\frac{0.4 \times 10^{-3}-z_{\mathrm{ev}}}{\pi \mu_{0} S_{0}}, \\
& R_{m 2}=\frac{\ln ((2 e+R) / R)}{2 \cdot \pi \cdot \mu_{0} \cdot l_{s}},
\end{aligned}
$$

where $0.4 \times 10^{-3}-z_{\text {ev }}$ denotes the length of the working air gap, $l_{s}$ denotes the width of the secondary air gap, $e$ denotes the length of the secondary air gap, and $R$ denotes the radius of the spool. The parameters are marked in Figure 2.

\subsection{Analysis of Electrical Characteristics of the Solenoid Valve} Spool. Coil magnetic field strength is mainly determined by two factors: one is the magnitude of current, and the other is the back electromotive force. Therefore, the loop control valve coil circuit model is

$$
u_{i}=i \cdot r+\frac{\partial \psi\left(i, z_{\mathrm{ev}}\right)}{\partial i} \dot{i}+\frac{\partial \psi\left(i, z_{\mathrm{ev}}\right)}{\partial s} \dot{z}_{\mathrm{ev}}
$$

where $r$ is the electric resistance of the solenoid coil, $\left(\partial \psi\left(i, z_{\text {ev }}\right) / \partial i\right) i$ denotes the back electromotive force (EMF) produced by the inductance of the coil, and $\left(\partial \psi\left(i, z_{\mathrm{ev}}\right) / \partial s\right) \dot{z}_{\mathrm{ev}}$ denotes the back EMF produced by the motion of the spool.

\subsection{Analysis of Hydraulic Characteristics of the Solenoid Valve} Spool. When the valve spool is opened by electromagnetic force, the velocity and direction of brake fluid will change. In this paper, the space between the spool and the oil inlet of the solenoid valve is taken as the research object, as shown in Figure 4. According to Leibniz Reynolds transmission theorem, the mathematical model of the object of study can be expressed as

$$
\frac{d}{\mathrm{~d} t} \iint_{V} \int \vec{v} \rho \mathrm{d} V=\oint_{V} F \mathrm{~d} S .
$$

Dimensional parameters of the space consisting of the spool and seat are substituted into equation (7), and then, we can get 


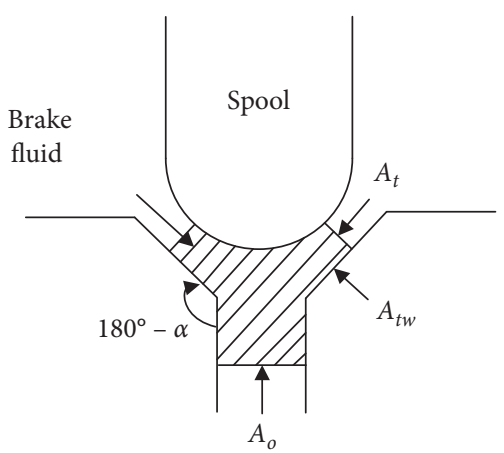

FIgURE 4: Schematic diagram of hydrodynamic force.

$$
\begin{aligned}
F_{s}= & \rho q_{\mathrm{ev}} v_{0}-\rho q_{\mathrm{ev}} v_{t} \cos \alpha+p_{m} A_{0}+c_{1} P_{t} A_{\mathrm{tw}} \sin \alpha \\
& -P_{w} A_{t} \cos \alpha-P_{w}\left(A_{0}+A_{\mathrm{tw}} \sin \alpha-A_{t} \cos \alpha\right),
\end{aligned}
$$

where $q_{\mathrm{ev}}$ denotes the flow rate through the valve, $\rho$ denotes the mass density of brake fluid, $v_{0}$ denotes the flow velocity of brake fluid passing through inlet section of the valve orifice, $A_{0}$ denotes the section area, $v_{t}$ is the average flow velocity at the throttle section, the section area is $A_{t}, P_{t}$ denotes the average pressure at the throttle section, $\alpha$ denotes half of the cone angle corresponding to the valve seat, $P_{m}$ denotes the average pressure at the inlet section of the valve orifice, the value of $P_{m}$ can be acquired by main cylinder pressure sensor, $P_{w}$ denotes the pressure of the brake cylinder, and $A_{\mathrm{tw}}$ denotes the cone-shaped wall area surrounding the throttle section. Considering the uneven pressure distribution of brake fluid on the surface $A_{\mathrm{tw}}$, the compensation coefficient $c_{1}$ is added.

The flow rate of brake fluid through the valve seat is expressed as

$$
q_{\mathrm{ev}}=c_{d} A_{t} \sqrt{\frac{2\left(P_{m}-P_{w}\right)}{\rho}}
$$

where $c_{d}$ represents the flow parameters of brake fluid.

According to Bernoulli equation in fluid mechanics,

$$
\begin{gathered}
P_{t}+\frac{1}{2} \rho v_{t}^{2}=P_{w}+\frac{1}{2}(1-\zeta) \rho v_{\mathrm{ev}}^{2} \\
A_{0} v_{0}=A_{t} v_{t}=A_{\mathrm{ev}} v_{\mathrm{ev}}
\end{gathered}
$$

where $v_{\mathrm{ev}}$ denotes the average flow velocity at the outlet section of the valve and $A_{\mathrm{ev}}$ denotes the section area of the valve. The brake fluid is affected by the friction of the pipe wall in the solenoid valve, so the mechanical energy loss coefficient of the brake fluid $\zeta$ is added.

Combining equations (9)-(11), $P_{w}$ can be expressed as

$$
P_{w}=P_{t}+c_{d}^{2}\left[(1+\zeta) \frac{A_{t}^{2}}{A_{\mathrm{ev}}^{2}}-1\right]\left(P_{m}-P_{w}\right) .
$$

Combining equations (8)-(12), steady state flow force on the spool can be expressed as

$$
F_{s}=\left[2 c_{d}^{2} A\left(t \frac{A_{t}}{A_{\mathrm{ev}}}-\cos \alpha\right)+A_{\mathrm{ev}}+c_{1} c_{d}^{2}\left((1+\zeta) \frac{A_{t}^{2}}{A_{\mathrm{ev}}^{2}}-1\right) A_{\mathrm{tw}} \sin \alpha\right] \cdot\left(P_{m}-P_{w}\right)
$$

When the solenoid valve is working, the spool will move up or down to change the wheel cylinder pressure. At this time, the transient flow force can be expressed as

$$
F_{\mathrm{st}}=\rho L_{h} c_{d} W \sqrt{\frac{2}{\rho}\left(P_{m}-P_{w}\right)} \dot{z}_{\mathrm{ev}}
$$

where $L_{h}$ represents the distance from $A_{0}$ to $A_{t}$. According to [21], the transient flow force is affected by the speed of spool movement and the pressure difference. When the pressure difference of the solenoid valve is $20 \mathrm{MPa}$ and the movement speed of the spool is $2 \mathrm{~m} / \mathrm{s}$, the transient hydrodynamic force is only $0.15 \mathrm{~N}$. The value of the transient flow force is smaller than that of the steady state flow force and is not the main factor affecting the movement of the spool, so the transient hydrodynamic force can be ignored [21, 22].

\section{Pressure Estimation and Pressure Control Methods}

The entire pressure estimation and pressure control system is shown in Figure 5. The whole system is mainly composed of four parts: pressure estimation module, pressure control module, pressure PID, and current PID. In the pressure estimation module, the spool position is obtained using the SRCKF algorithm. The input of spool position estimation algorithm is $u_{i}, i$, and $F_{s}$. Both $u_{i}$ and $i$ are measured using sensors mounted on solenoid valves. $F_{s}$ is calculated by equation (13). After the spool position is obtained, the wheel cylinder pressure can be calculated by the method described below.

In the pressure control algorithm, a spool position controller based on the sliding mode algorithm is adopted to adjust the WCP. The input of pressure control algorithm is spool position $z_{\mathrm{ev}}$ and desired spool position $z_{\text {nom }}$. The relationship between nominal spool position $z_{\text {nom }}$ and WCP is a nonlinear state equation, so it is necessary to convert WCP to $z_{\text {nom }}$ through the PID algorithm. The output of pressure control algorithm is the desired coil current. But the solenoid valve is driven by PWM. Therefore, the PID algorithm is used to convert the current to PWM.

4.1. Introduction of Wheel Cylinder Pressure Estimation Method. The calculation method of the brake wheel cylinder pressure is mainly based on the $\mathrm{P}-\mathrm{V}$ characteristic curve of the brake fluid. The volume increase of the brake fluid volume in each control cycle plus the original brake fluid 


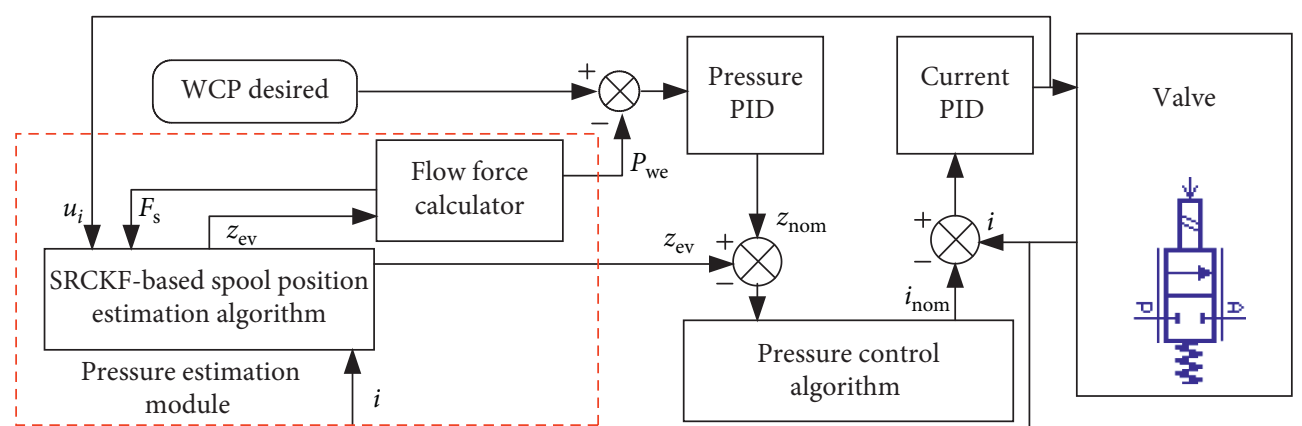

FIgURE 5: Overall structure diagram of the pressure estimation and pressure control system.

volume can be used to obtain the total volume in the wheel cylinder. Then, the P-V characteristic curve check table can be used to obtain the pressure value in the brake wheel cylinder.

4.1.1. Calculation of Wheel Cylinder Pressure during the Stage of Increasing Pressure. The brake fluid volume increment is determined by the opening of the valve. The volume increase of the brake fluid is as follows:

$$
\Delta V=\int q_{\mathrm{ev}} \mathrm{d} t
$$

where $q_{\mathrm{ev}}$ denotes the brake fluid flow rate during pressurization.

The calculation method of the wheel cylinder pressure in the pressurization stage is shown in Figure 6. The brake fluid flow rate in the increasing pressure phase is determined by the displacement of the valve spool. The spool position is determined by the valve coil current. Therefore, the solution of the spool displacement is the key to the calculation of the wheel cylinder pressure.

Combining equations (1) and (6), the equation of state for the displacement of solenoid valve spool and coil current can be obtained as follows:

$$
\left[\begin{array}{c}
\dot{x}_{1} \\
\dot{x}_{2} \\
\dot{x}_{3}
\end{array}\right]=\left[\begin{array}{c}
\frac{u_{i}}{A\left(i, z_{\mathrm{ev}}\right)}-\frac{r}{A\left(i, z_{\mathrm{ev}}\right)} x_{1}-\left(i, z_{\mathrm{ev}}\right) \\
x_{3} \\
\frac{1}{m}\left(F_{m}\left(i, z_{\mathrm{ev}}\right)-F_{s}\left(\Delta P, z_{\mathrm{ev}}\right)-F_{k}\left(z_{\mathrm{ev}}\right)-C u \cdot x_{3}\right) \\
y=[100] x,
\end{array}\right] \text {, }
$$

where the state variable is $x=\left[x_{1}, x_{2}, x_{3}\right]^{T}=\left[i, z_{\mathrm{ev}}, \dot{z}_{\mathrm{ev}}\right]^{T}$, $A=\partial \psi\left(i, z_{\mathrm{ev}}\right) / \partial i, \quad B=\partial \psi\left(i, z_{\mathrm{ev}}\right) / \partial z_{\mathrm{ev}}, \quad y=\left[\begin{array}{ccc}i & 0 & 0\end{array}\right]$, and $F_{s}\left(\Delta P, z_{\mathrm{ev}}\right)$ can be obtained by equation (13).

For equation (16), the SRCKF algorithm is used to estimate the spool displacement and coil current. The SRCKF algorithm is shown in Figure 7.

As can be seen from Figure 4, the mathematical model of the spool displacement and the control valve orifice area is

$$
A_{t}=\pi\left[\left(\sqrt{\frac{A_{o}}{\pi}}+z \cos \alpha\right)^{2}-\frac{A_{o}}{\pi}\right] .
$$

Combining equations (17) and (9), the flow rate of the solenoid valve during the increase phase can be obtained:

$$
q_{\mathrm{ev}}=c_{d} \pi\left[\left(\sqrt{\frac{A_{o}}{\pi}}+z \cos \alpha\right)^{2}-\frac{A_{o}}{\pi}\right] \sqrt{\frac{2\left(P_{m}-P_{w}\right)}{\rho}} .
$$

Combining equations (17) and (18), the pressure of the wheel cylinder can be obtained:

$$
P_{\mathrm{we}}=c_{d} K\left(P_{w}\right) \int_{0}^{t} A_{t}(z) \operatorname{sgn}\left(P_{m}-P_{w}\right) \sqrt{\frac{2\left|P_{m}-P_{w}\right|}{\rho}} \mathrm{d} t .
$$

4.1.2. Calculation of Wheel Cylinder Pressure during the Stage of Pressure Reduction. During the phase, the brake fluid increment can be expressed as

$$
\Delta V=-\int q_{\mathrm{av}} \mathrm{d} t,
$$

where $q_{\text {av }}$ denotes the flow rate of the brake fluid during decompression. Since the valve port is fully open during the depressurization phase, the brake fluid flow is available according to the Bernoulli equation:

$$
q_{\mathrm{av}}=c_{d} A_{\mathrm{av}} \sqrt{\frac{2\left(P_{\mathrm{wc}}-P_{\mathrm{accu}}\right)}{\rho} .}
$$

Then, the flow rate is integrated, and the volume increase of the brake fluid during the decompression phase can be obtained:

$$
\Delta V=-\int c_{d} A_{\mathrm{av}} \sqrt{\frac{2\left(P_{\mathrm{wc}}-P_{\mathrm{accu}}\right)}{\rho \mathrm{d} t}} .
$$

Finally, by adding the original brake fluid volume and the current volume increment, the cylinder pressure in the brake wheel cylinder during the decompression stage can be obtained by using the PV characteristic curve look-up table method:

$$
P=f_{\mathrm{pv}}\left(V_{w}+\Delta V\right) .
$$




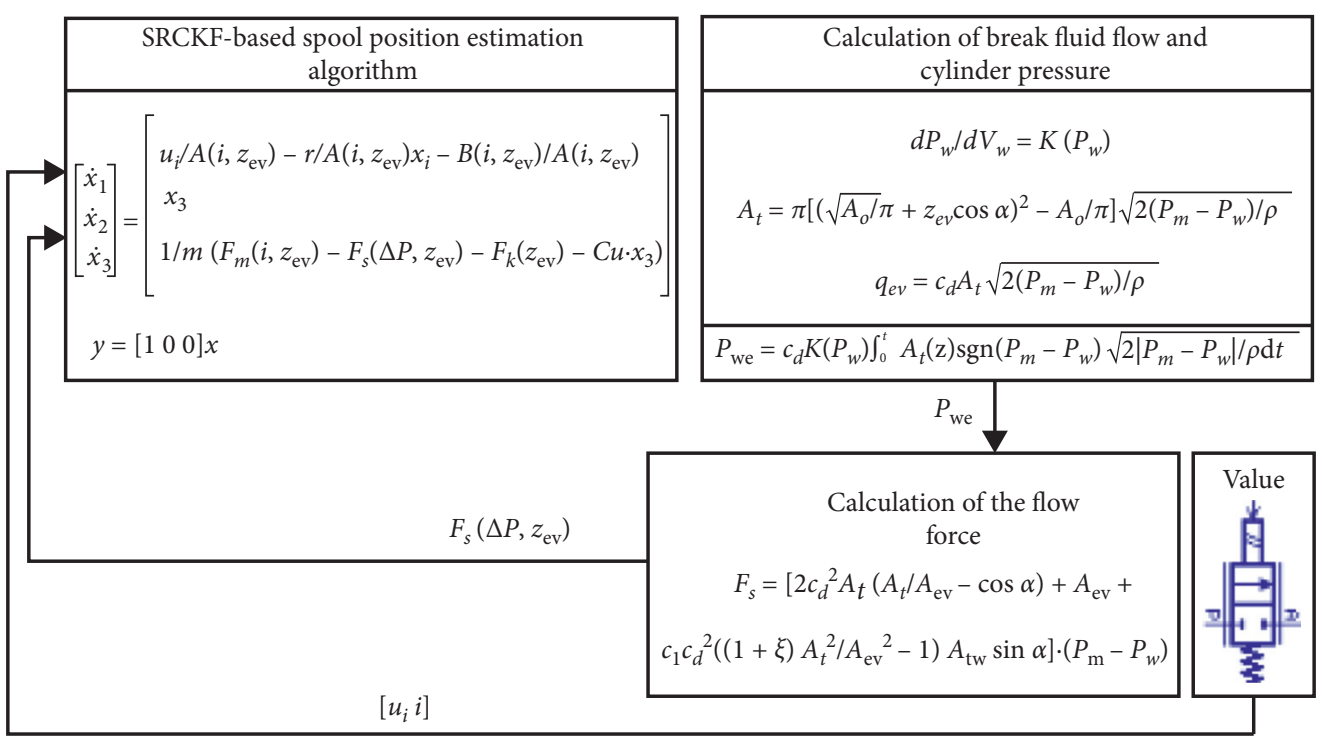

FIGURE 6: Schematic diagram of a method to calculate cylinder pressure.

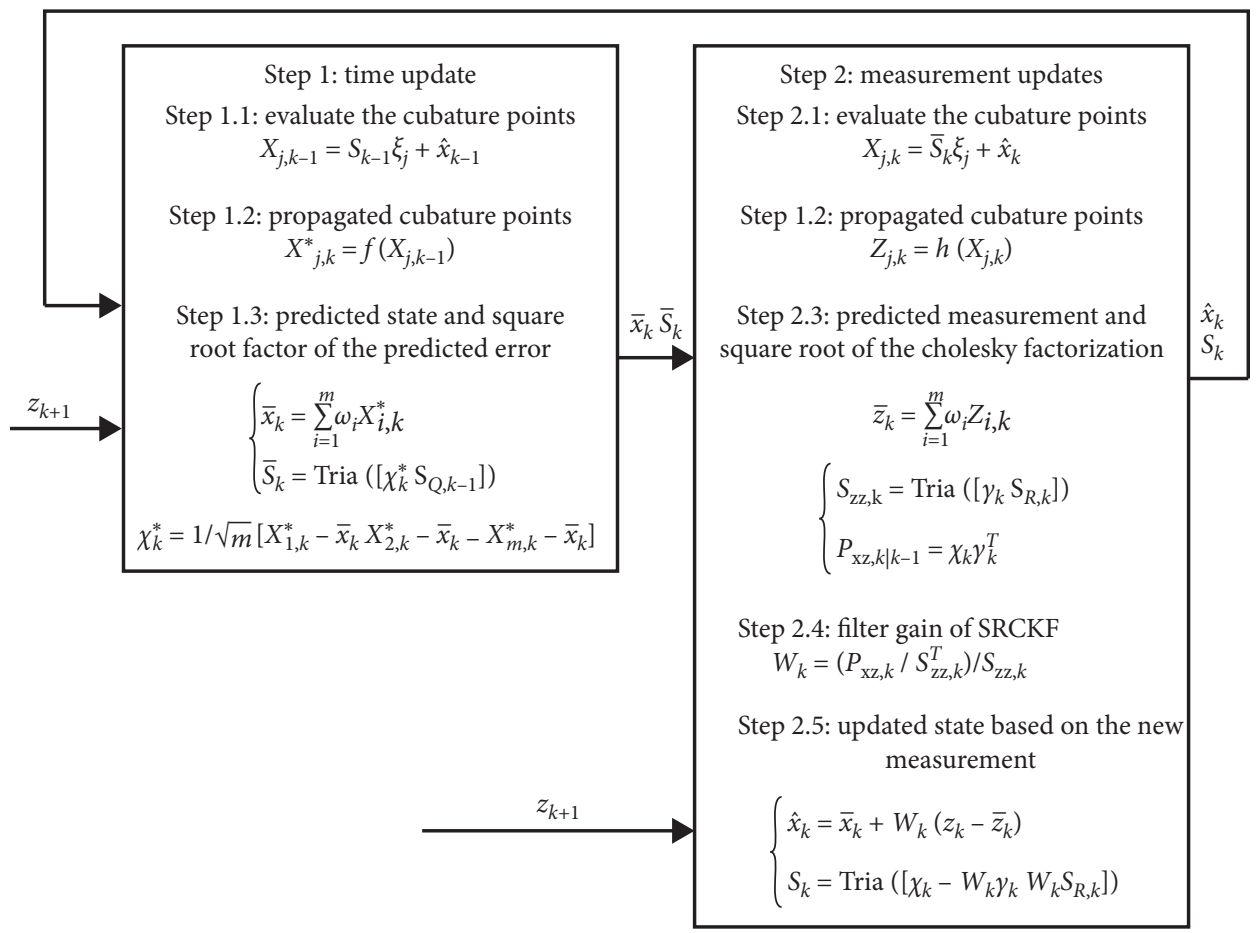

FIGURE 7: Schematic diagram of SRCKF.

4.2. Wheel Cylinder Pressure Control Method. The pressure control of the valve is also divided into a pressure increasing phase and a pressure reducing phase. The two phases are controlled differently. During the decompression phase, the valve port is completely opened to achieve the purpose of rapid decompression. The control method in the pressure increasing phase is relatively more complicated than that in the pressure reducing phase. The pressure control strategy in the pressure increasing phase is shown in Figure 5. The input parameters mainly include the estimated value of the wheel cylinder pressure, the target value of the wheel cylinder pressure, and the displacement of the solenoid valve spool. The control signal in the control strategy is the PWM duty cycle, which can be obtained by coil current conversion.

The analysis in Section 4.1.1 shows that the brake fluid flow rate is $q_{\mathrm{ev}}=c_{d} A_{t} \sqrt{2\left(P_{m}-P_{w}\right) / \rho}$, and the flow area $A_{t}$ varies with the valve spool displacement in the pressure increasing phase. The valve spool displacement is determined by the coil current. Therefore, by adjusting the coil current, the increment of brake fluid can be controlled in the pressure increasing phase, and then the brake wheel cylinder pressure can be controlled. 
As shown in Figure 8, the conversion between the target value of coil current and the target value of PWM signal depends on the PID algorithm:

$$
\begin{aligned}
D_{\mathrm{pwm}} & =K_{\mathrm{p} \_ \text {duty }} \Delta i_{e}(t)+K_{\mathrm{i} \_ \text {duty }} \int \Delta i_{e} \mathrm{~d} t+K_{\mathrm{d} \_ \text {duty }}\left(\Delta i_{e}(t)-\Delta i_{e}(t-1)\right), \\
\Delta i_{e} & =i_{\text {nom }}-i
\end{aligned}
$$

where $D_{\text {pwm }}$ denotes the target value of PWM signal, $K_{\mathrm{p}_{\text {d duty }}}$ denotes the proportional coefficients of the PID algorithm, $K_{\text {i_duty }}$ denotes the integral coefficients of the PID algorithm, $K_{\text {d_duty }}$ denotes the differential coefficients of the PID algorithm, $i_{\text {nom }}$ denotes the target value of coil current, and $i$ denotes the actual value of solenoid valve coil.

Similarly, the target value of the wheel-cylinder pressure and the target value of the spool distance are converted by the PID algorithm:

$$
\begin{aligned}
z_{\text {nom }} & =K_{p_{-} p} \Delta P_{e}(t)+K_{i_{-} p} \int \Delta P_{e}(t) \mathrm{d} t+K_{d_{-} p}\left(\Delta P_{e}(t)-\Delta P_{e}(t-1)\right), \\
\Delta P_{e}(t) & =P_{\text {nom }}-P_{\text {we }},
\end{aligned}
$$

where $z_{\text {nom }}$ denotes the target value of the valve spool distance, $K_{\text {p_duty }}$ denotes the proportional coefficients of the PID algorithm, $K_{\text {i_duty }}$ denotes the integral coefficients of the PID algorithm, $K_{\text {d_duty }}$ denotes the differential coefficients of the PID algorithm, $P_{\text {nom }}$ denotes the wheel cylinder pressure control target value, and $P_{\text {we }}$ denotes the current brake pressure of the brake wheel cylinder.

Relying on the PID algorithm, the control of the brake wheel cylinder pressure is converted to the control of the valve spool displacement. Then, the sliding mode variable structure control algorithm is used to solve the nonlinear problem between the wheel cylinder pressure and the valve spool displacement.

The sliding-mode surface is chosen as

$$
s=\dot{z}_{\mathrm{ev}}-\dot{z}_{\mathrm{nom}}+k_{x}\left(z_{\mathrm{ev}}-z_{\mathrm{nom}}\right),
$$

where $k_{x}$ is the weight factor ; when $s$ is equal to 0 , then $\dot{z}_{\text {ev }}-\dot{z}_{\text {nom }} \longrightarrow 0$ and $\left(z-z_{\text {nom }}\right) \longrightarrow 0$.

By differentiating $s$, thus the following equation is derived :

$$
\dot{s}=\ddot{z}_{\mathrm{ev}}-\ddot{z}_{\mathrm{nom}}+k_{z} \cdot\left(\dot{z}_{\mathrm{ev}}-\dot{z}_{\mathrm{nom}}\right) .
$$

Exponential reaching law is chosen:

$$
\ddot{z}_{\mathrm{ev}}-\ddot{z}_{\mathrm{nom}}+k_{x}\left(\dot{z}_{\mathrm{ev}}-\dot{z}_{\mathrm{nom}}\right)=-\varepsilon s g n(s)-k_{s} s .
$$

According to equations (1)-(3), the following equation is derived:

$$
\ddot{z}_{\mathrm{ev}}=\frac{i^{2} n^{2}}{2 \mu_{0} S_{0}\left(\left(0.4 \times 10^{-3}-z_{\mathrm{ev}} / \pi \mu_{0} S_{0}\right)+\left(\ln ((2 e+R) / R) / 2 \cdot \pi \cdot \mu_{0} \cdot l_{s}\right)\right)^{2}}+\frac{-F_{s}-F_{k}-C u \cdot \dot{z}_{\mathrm{ev}}}{m}
$$

According to equations (27) and (29), the following equation is derived:

$$
\begin{aligned}
& i^{2} J\left(z_{\mathrm{ev}}\right)+L\left(z_{\mathrm{ev}}, \dot{z}_{\mathrm{ev}}, \Delta P\right)-\ddot{z}_{\mathrm{nom}}+k_{x}\left(\dot{z}_{\mathrm{ev}}-\dot{z}_{\mathrm{nom}}\right)=-\varepsilon \operatorname{sgn}(s)-k_{s} s, \\
& J(x)=\frac{n^{2}}{2 \mu_{0} S_{0}\left(\left(0.4 \times 10^{-3}-z_{\mathrm{ev}} / \pi \mu_{0} S_{0}\right)+\left(\ln ((2 e+R) / R) / 2 \times \pi \times \mu_{0} \times l_{s}\right)\right)^{2}}, \\
& L\left(z_{\mathrm{ev}}, \dot{z}_{\mathrm{ev}}, \Delta P\right)=\frac{-F_{s}-F_{k}-C u \cdot \dot{z}_{\mathrm{ev}}}{m} .
\end{aligned}
$$




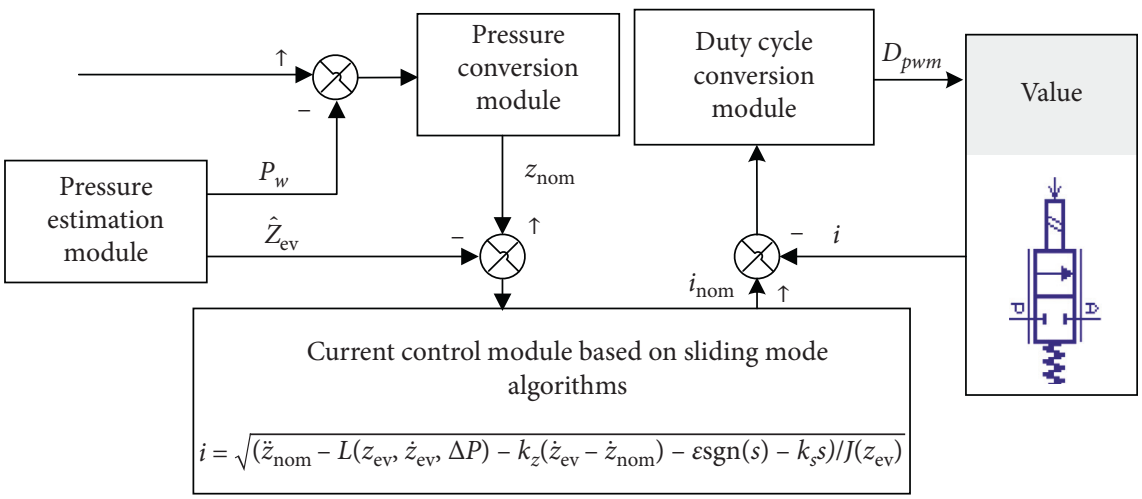

Figure 8: Schematic diagram of cylinder pressure control strategy.

The relationship between the target value of brake wheel cylinder pressure and the target value of solenoid valve coil current is as follows:

$$
i=\sqrt{\frac{\left(\ddot{z}_{\mathrm{nom}}-L\left(z_{\mathrm{ev}}, \dot{z}_{\mathrm{ev}}, \Delta P\right)-k_{z}\left(\dot{z}_{\mathrm{ev}}-\dot{z}_{\mathrm{nom}}\right)-\varepsilon \operatorname{sgn}(s)-k_{s} s\right)}{J\left(z_{\mathrm{ev}}\right)} .}
$$

\section{Simulation Results}

The brake wheel cylinder pressure estimation and control algorithms mentioned in this paper are verified by software cosimulation. Software cosimulation is shown in Figure 9. Both pressure estimation and pressure control algorithms were modeled using Matlab/Simulink software. The solenoid valve in the simulation is modeled by Simulink, and the other hydraulic components are modeled by Amesim.

The execution period of pressure estimation algorithm and pressure control algorithm is $10 \mathrm{~ms}$. The pressure estimation algorithm requires the solenoid valve opening time parameter, which is calculated by the pressure control algorithm. The pressure control algorithm section requires the wheel cylinder pressure target value and the pressure estimate difference. The coil current, voltage parameters, and master cylinder pressure are used as input parameters to the pressure estimation algorithm model and the control algorithm model, respectively.

Parameters of the valve model are listed in Table 1. Parameters can be referred from [23-25].

\subsection{Verification of Solenoid Valve Spool Position Estimation.} The key to the accuracy of the pressure value lies in the spool displacement estimation. Therefore, the spool displacement estimation algorithm needs to be verified. In the simulation verification, the spool stroke of the solenoid valve is forced to make a cosine curve. The purpose of this is to verify the spool estimation algorithm based on SRCKF. During this process, the MCP is set to make a step change every $37.5 \mathrm{~ms}$ to see whether SRCKF is robust to MCP changes. The simulation curve is shown in Figures 10-13.

As shown in Figure 10, despite the error, the observed curve still tracks the actual spool position well. The absolute error between the actual position of the spool and the

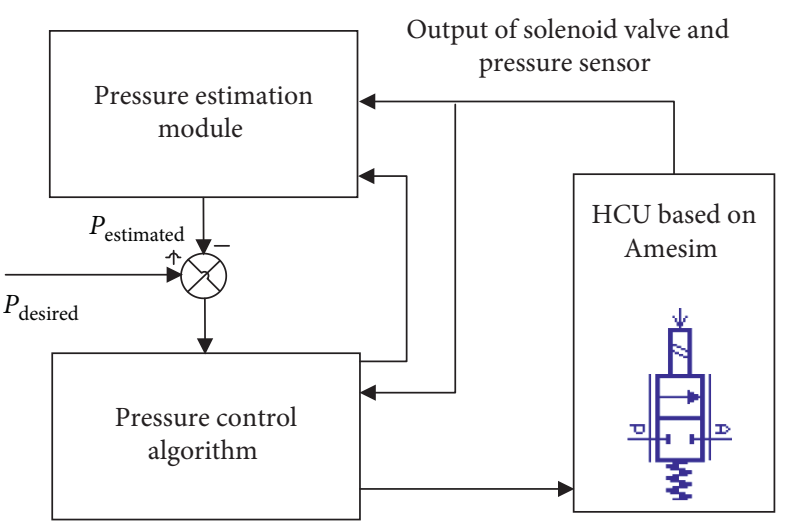

Figure 9: Schematic diagram of software cosimulation.

Table 1: Parameters of the valve model.

\begin{tabular}{lcc}
\hline Variable & Symbol & Value \\
\hline Mass of the valve spool & $m$ & $0.004 \mathrm{~kg}$ \\
Number of valve coil windings & $n$ & 300 \\
The area of the magnetic pole & $S_{0}$ & $10^{-4} \mathrm{~m}^{2}$ \\
Preload force of spring & $F_{0}$ & $1 \mathrm{~N}$ \\
Stiffness coefficient of the return spring & $K_{k}$ & $1000 \mathrm{~N} / \mathrm{m}$ \\
Width of secondary air gap & $l_{s}$ & $6 \times 10^{-4} \mathrm{~m}$ \\
Radius of the spool & $R$ & $7 \times 10^{-3} \mathrm{~m}$ \\
Electric resistance of the solenoid coil & $r$ & $6 \Omega$ \\
Mass density of brake fluid & $\rho$ & $860 \mathrm{~kg} / \mathrm{m}^{3}$ \\
Inlet section area of valve & $A_{0}$ & $3.8 \times 10^{-7} \mathrm{~m}^{2}$ \\
Cone angle of valve seat & $2 \alpha$ & $120 \mathrm{deg}$ \\
\hline
\end{tabular}

estimated value is within $0.01 \mathrm{~mm}$. The changes in MCP and WCP have little effect on the error of spool position estimation, which proves the robustness of SRCKF. It can be seen from Figure 10 that the estimated value of coil current is also consistent with the real value.

5.2. Verification of Pressure Estimation. Firstly, the wheel cylinder pressure estimation algorithm is verified. Figure 14 shows the valve control command. The duty cycle of the PWM starts from $40 \%$, and the cycle is boosted by $10 \%$ in 0.02 s. After reaching $100 \%$, it is restored to $40 \%$. As shown in Figure 15, the master cylinder pressure is set to vary 


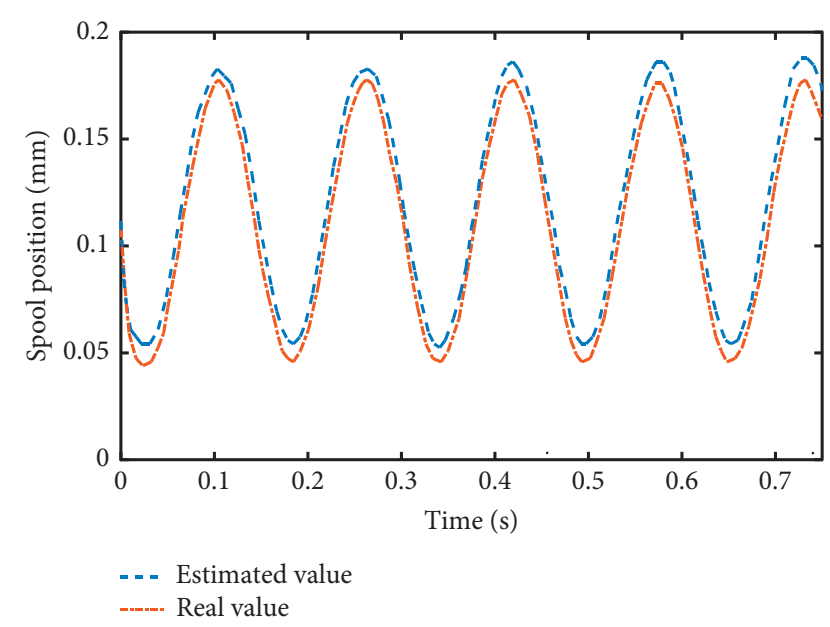

FIgURE 10: The curve of estimated spool position value and real value.

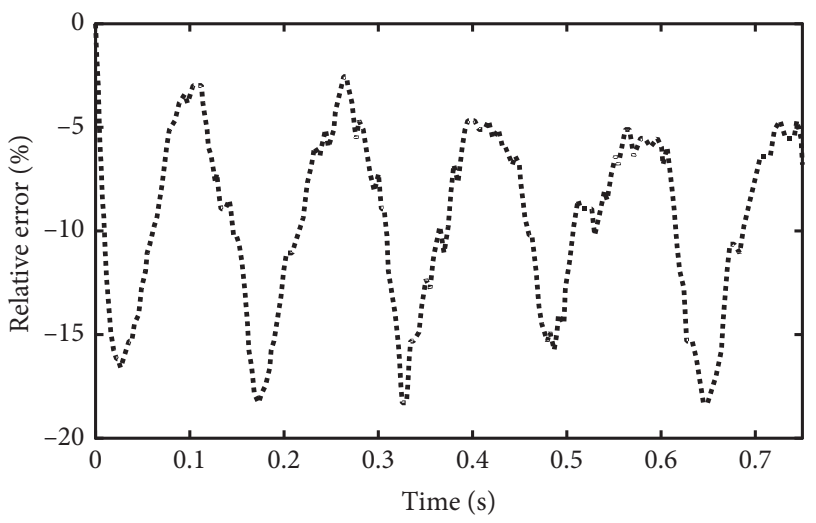

FIgURE 11: The relative error between estimated spool position value and real value.

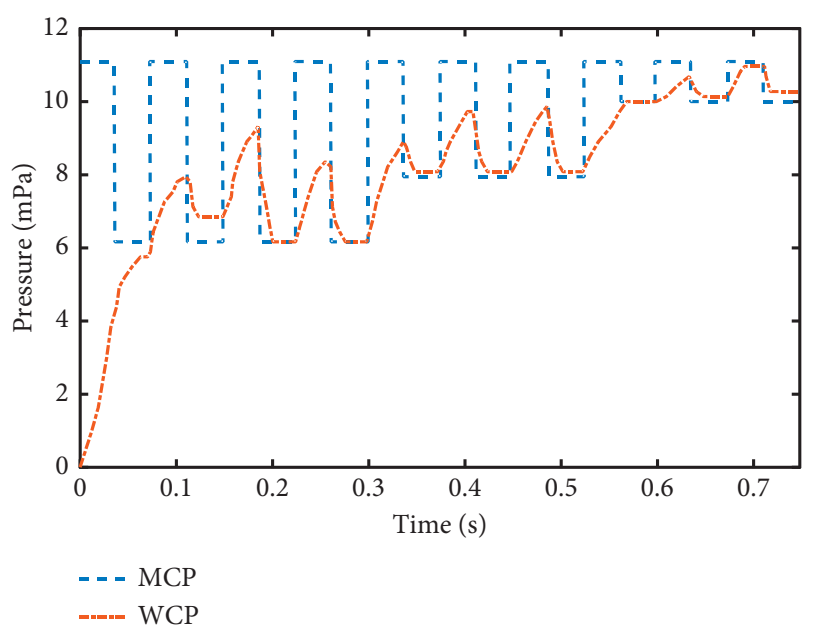

Figure 12: The curve of MCP and WCP.

between 30 bar and 80 bar. This setting is to simulate the driver's emergency braking under dangerous driving conditions. As shown in Figure 15, the estimated value of the

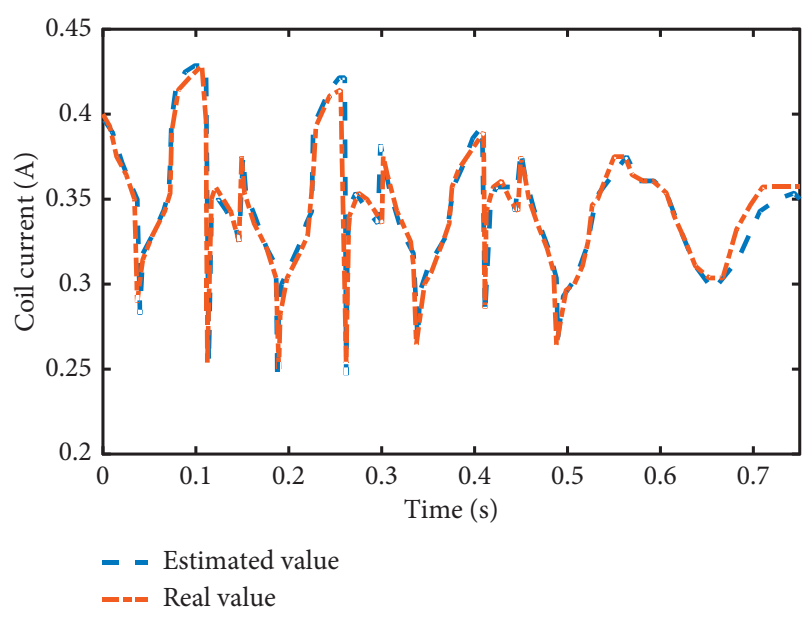

FIGURE 13: The curve of estimated coil current value and real value.

wheel cylinder pressure and the actual value substantially coincide. Figure 16 shows the deviation curve between the estimated value and the actual value. It can be seen that the deviation rate between the estimated value and the actual value is about $+6 \%$.

5.3. Verification of Pressure Control. The simulation verification results of the wheel cylinder pressure control algorithm are shown in Figures 17-19. The master cylinder pressure is set in AMESim to reach 90 bar in about 0.05 seconds and is kept constant. Figure 17 shows the simulation verification effect of the pressure control. The actual value of the wheel cylinder pressure basically coincides with the target value. As shown in Figure 18, the error is relatively large at $0.1 \mathrm{~s}, 0.25 \mathrm{~s}$, and $0.4 \mathrm{~s}$. It is caused by the integral operation in the wheel cylinder pressure estimation algorithm. As can be seen from Figure 19, the actual value of the spool distance closely follows the target value. The actual value of the spool displacement closely follows the target value. At the initial stage of boosting, the spool is fully opened, and the brake wheel cylinder pressure is increased at the highest rate. When the actual value is gradually equal to the target value, the spool displacement is gradually zeroed to reduce the boost rate.

\section{Experiments}

In this paper, the pressure estimation and wheel cylinder pressure control algorithm designed in this paper are verified by software simulation. Then, the hardware-in-loop experiment is used to further verify the algorithm. The bench is shown in Figure 20, and the symbol 1 shows the brake and brake wheel cylinder of the rear axle of the car. The symbol 2 is the PXI chassis of National Instruments. The device numbered 3 is a controller that is responsible for running the pressure estimation and pressure control algorithm. The device numbered 4 is a computer workstation responsible for compiling and downloading the algorithm into the controller. The devices numbered 5 and 6 are, respectively, the automobile steering wheel and the brake pedal. The 


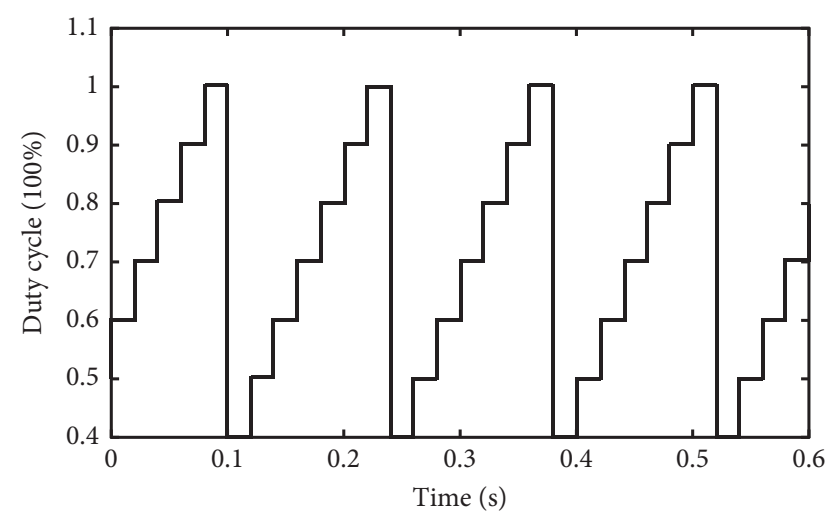

Figure 14: Schematic diagram of solenoid valve control instruction.

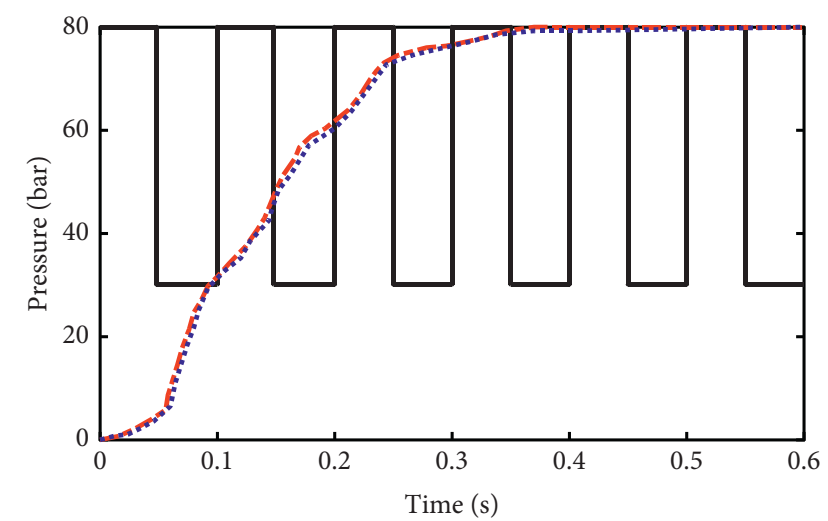

- Master cylinder pressure

--- Estimation of pressure

...... Real value of pressure

FIgUre 15: Curve of estimated pressure value.

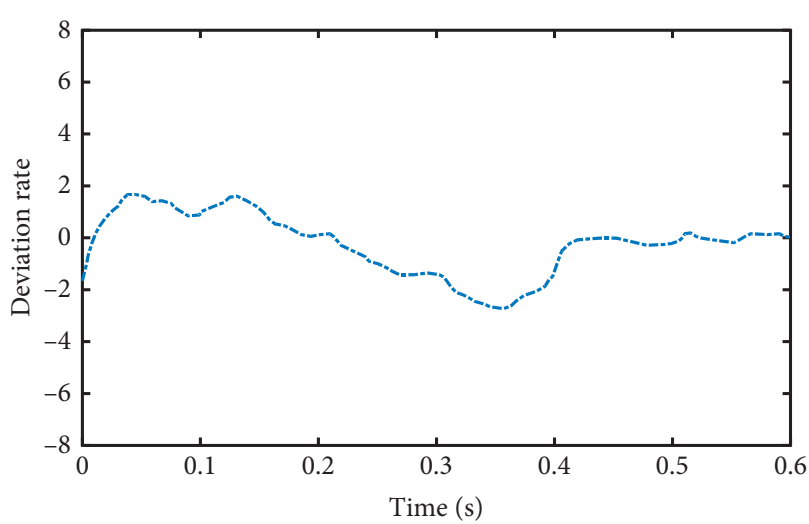

FIgURE 16: Curve of error value.

device numbered 7 is the accelerator pedal. The device numbered 8 is a brake caliper of the front axle, and the device shown by reference numeral 9 is a wheel cylinder pressure sensor for collecting wheel cylinder pressure data. The device shown at 10 is a solenoid valve driving circuit board. The

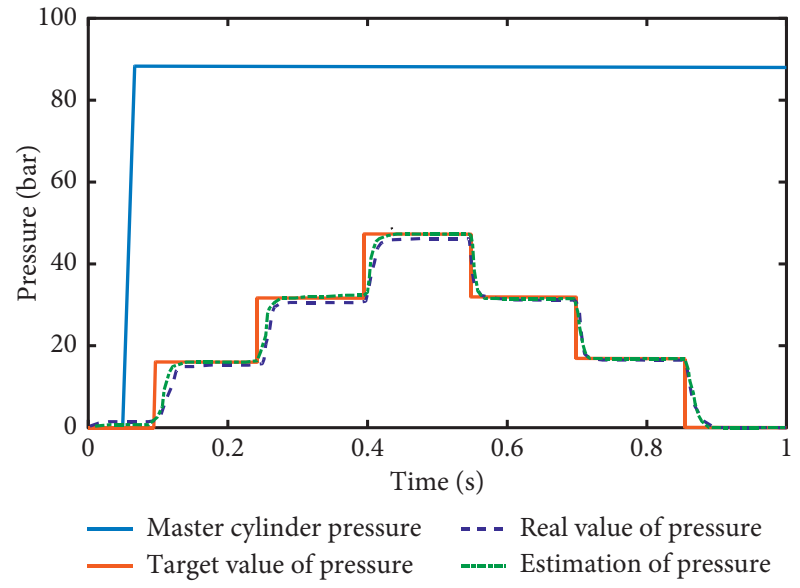

FIGURE 17: Curve of estimated and actual cylinder pressure.

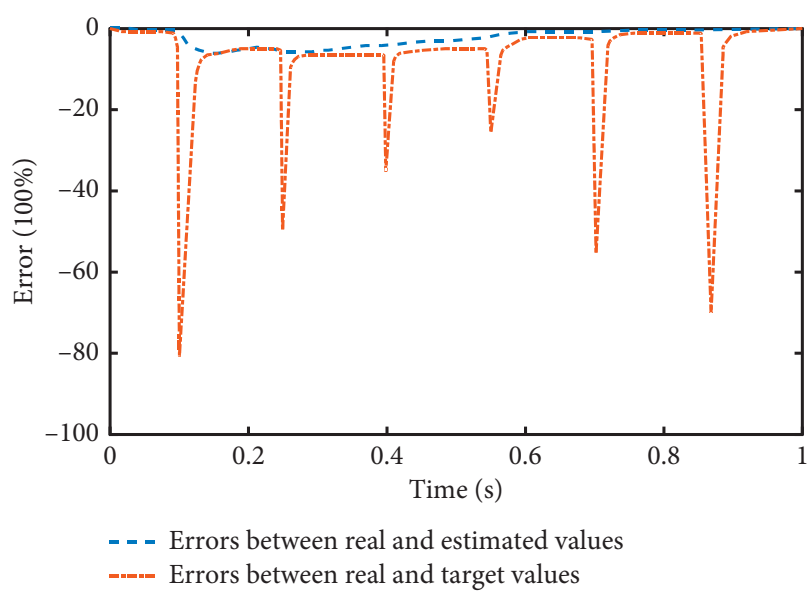

Figure 18: Curve of error value.

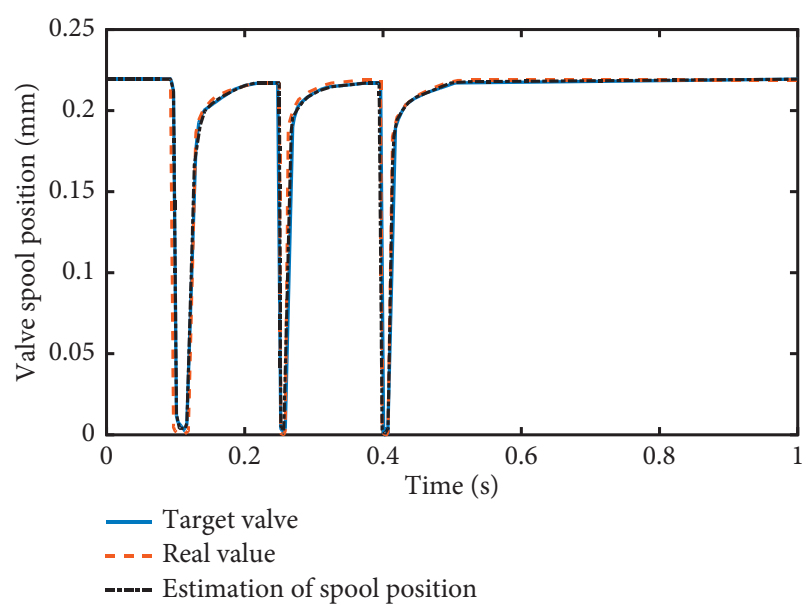

Figure 19: Curve of valve spool position.

numeral 11 is an $\mathrm{HCU}$, and the numeral 12 is a main cylinder.

As shown in Figure 21, at the beginning of the experiment, the master cylinder pressure was stabilized at 80 bar by 


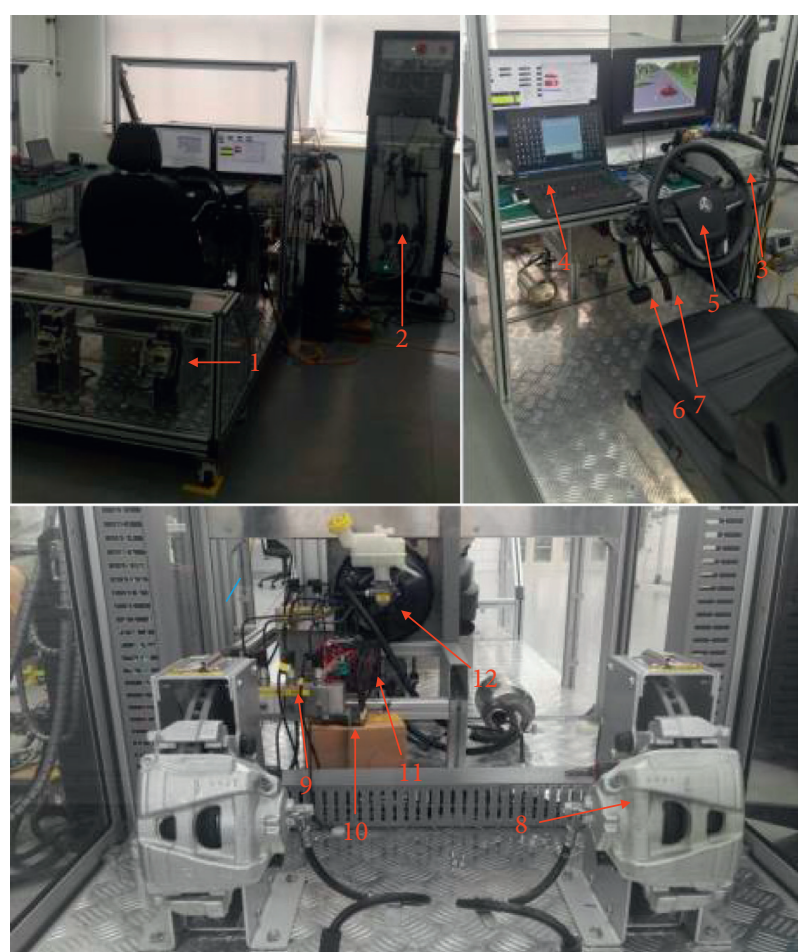

Figure 20: Architecture diagram of HIL.

means of a motor pump. The wheel cylinder pressure increased from 5 seconds, and the wheel cylinder pressure reached 65.2 bar at 5.506 seconds. The supercharging rate reached $129 \mathrm{bar} / \mathrm{s}$ during the entire pressurization process, which was basically consistent with the target value. Figure 22 shows the valve coil current measurement data and the target value data curve. It can be seen that the coil current measurement value and the target value are basically consistent. Therefore, it can be determined that the position of the solenoid valve spool can be accurately controlled, and it can be determined that the algorithm can accurately control the brake fluid flow.

Figure 23 shows the measured data of the wheel cylinder pressure under the stepped boost condition. Under this condition, the master cylinder pressure data are always maintained at around $110 \mathrm{bar}$. At the start of the experiment for 3 seconds, the controller controls the solenoid valve to pressurize. After $40 \mathrm{~ms}$, the brake wheel cylinder pressure reached the target value of 20 bar. After another 0.2 seconds, the pressure is again increased. As shown in Figure 23, SRCKF, extended Kalman filter (EKF), and unscented Kalman filter (UKF) are used to estimate the wheel cylinder pressure, respectively. The value estimated by other filter methods has more error than the value estimated by SRCKF. The SRCKF-based estimation algorithm shows more accuracy than other methods. There is a small difference between the actual value and the value estimated by SRCKF. Figure 24 shows the valve coil current data. At 3 seconds, 3.2 seconds, 3.4 seconds, and 3.6 seconds, the loop control valve coil current rapidly drops to zero and the spool position reaches a maximum. At this time, the brake fluid quickly flows into the brake wheel cylinder to ensure that the wheel cylinder

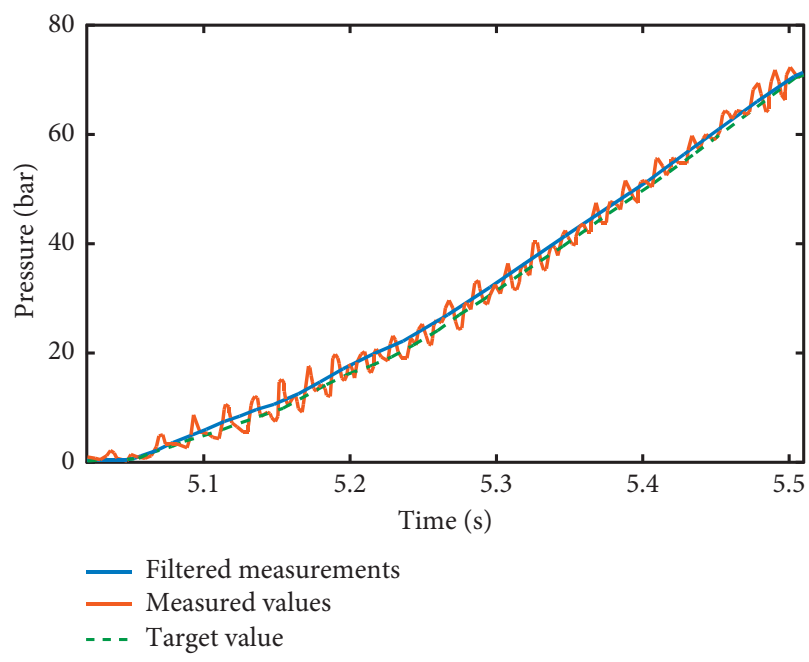

Figure 21: Curve of data detail.

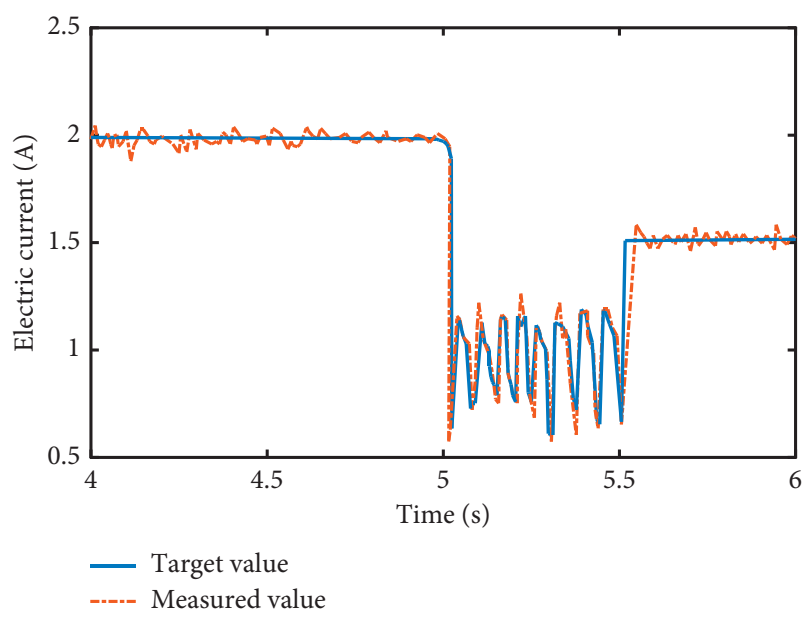

Figure 22: Curve of coil current.

pressurization rate reaches the maximum. This ensures that the wheel cylinder pressure closely follows the target value.

In order to compare the pressure control effects of the proposed pressure control method and the on-off threshold control method, a slope WCP increase test was implemented. This method has been introduced in many references $[26,27]$. The result of on-off threshold is shown in Figure 25. Unlike the linear controller, the solenoid valve current can only be switched on or off, so the spool position is fully opened or closed. The wheel cylinder pressure cannot accurately follow the target value, and the error is large. Figure 26 shows the coil current curve, and the coil current can only be fully opened or completely closed.

Figure 27 shows the result of the slope WCP increase controlled by the proposed method. The filtered WCP can follow the desired WCP pressure well by the switching valve. The control effect of proposed method by the switch value is similar to the effect of using a proportional valve in [28]. Figure 28 shows the coil current curve controlled by the proposed method. 


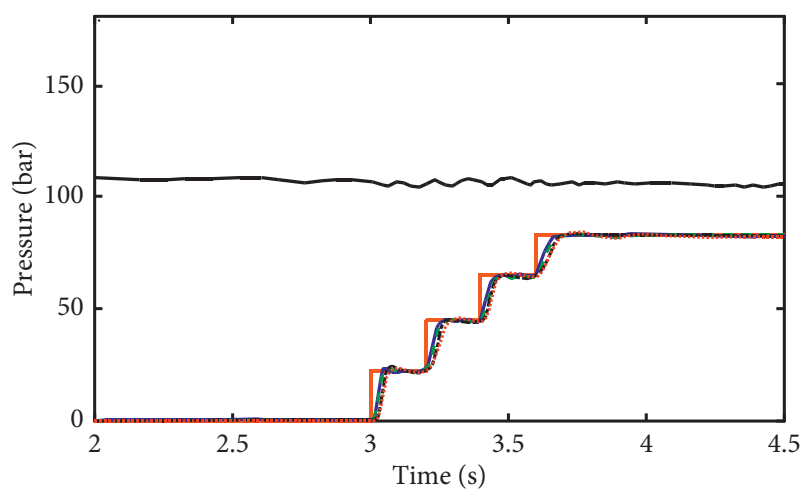

$\begin{array}{ll}\text { — Pressure of master cylinder } & --- \text { SRCK } \\ \text { — Target value of cylinder pressure } & --.-- \text { UKF } \\ \text { — Cylinder pressure } & \text {-......... EKF }\end{array}$

FIgURE 23: Curve of stepped pressurization.

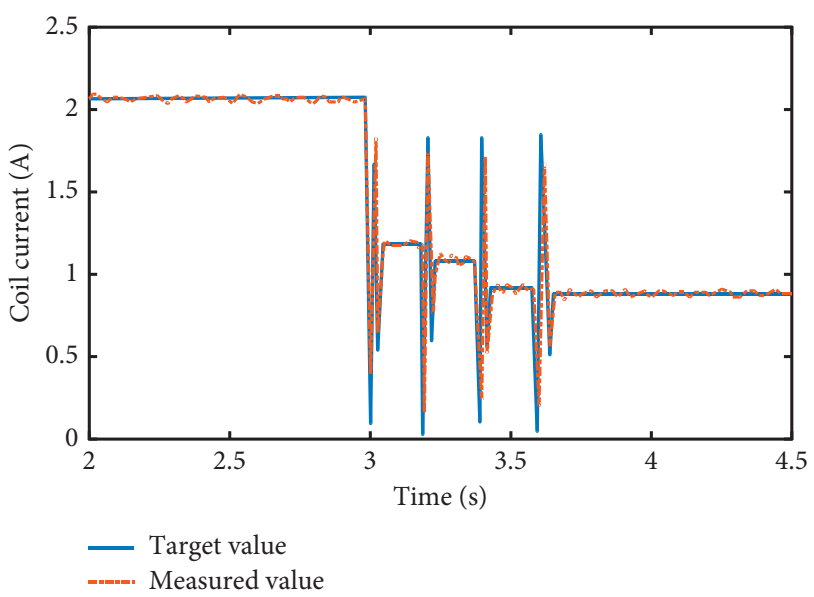

Figure 24: Curve of coil current.

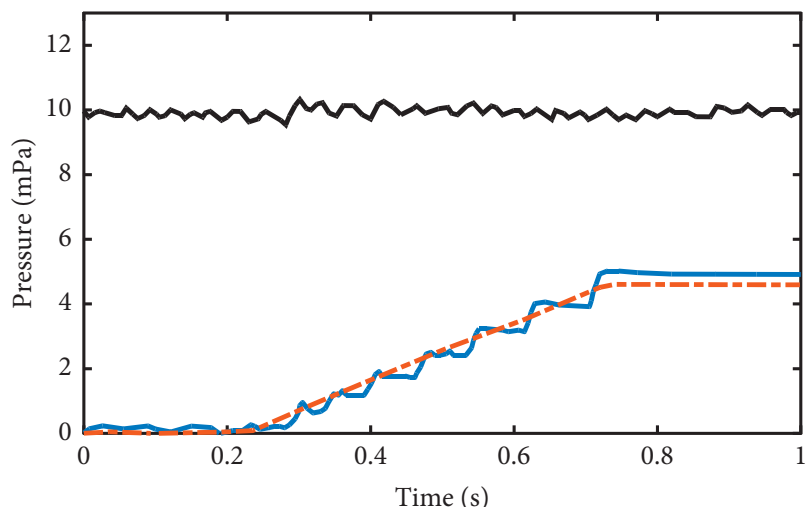

— WCP filtered

--s Desired WCP

- MCP

FIGURE 25: The curve of WCP pressure used by on-off threshold control.

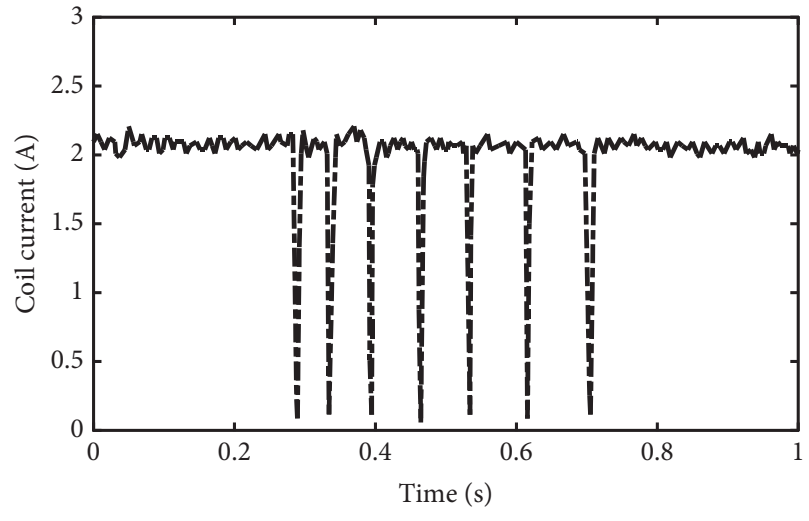

--- Measured value

FIGURE 26: The curve of coil current used by on-off threshold control.

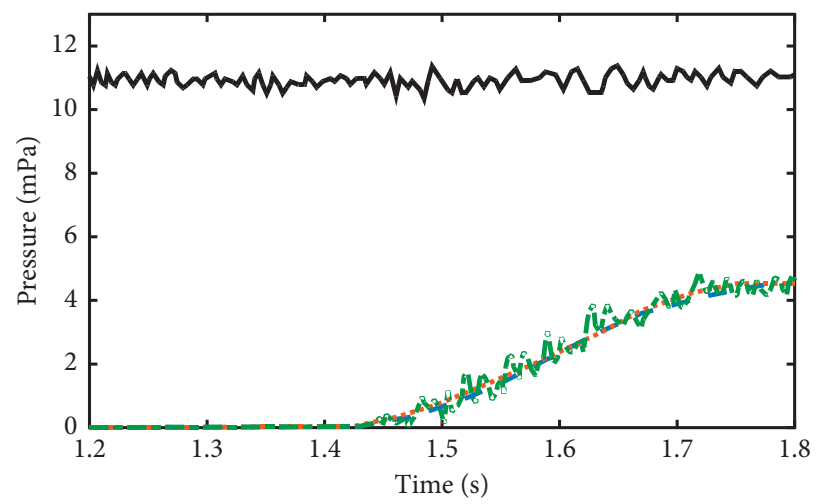

$$
\begin{aligned}
& \text { - - WCP filtered } \\
& \text {...... WCP desired }
\end{aligned}
$$

FIgURE 27: The curve of WCP pressure used by the proposed control method.

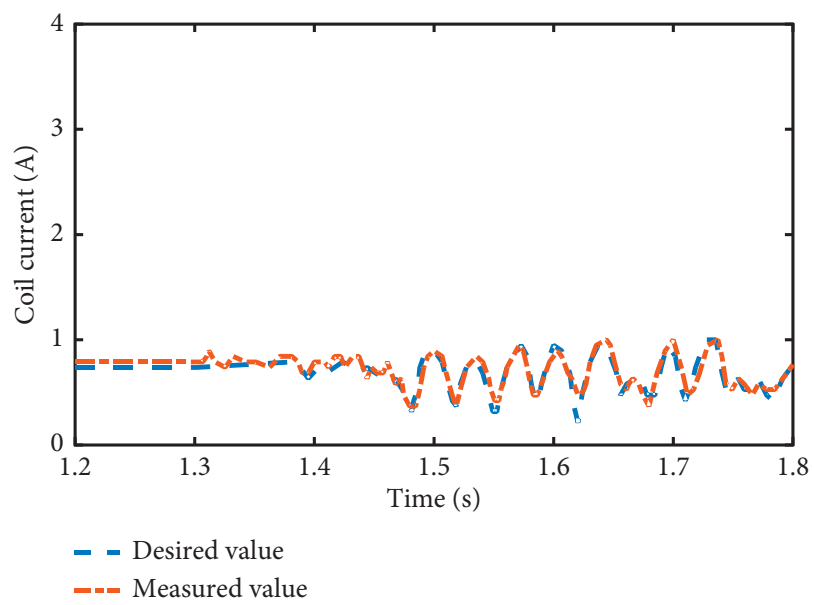

FIgURE 28: The curve of coil current used by the proposed control method. 


\section{Conclusion}

Firstly, this paper studies the working mechanism and characteristics of the solenoid valve of HCU. Then, according to the PV characteristics, the pressure estimation algorithm and pressure control method of brake wheel cylinder are designed. Finally, the pressure estimation and pressure control algorithm are verified by HIL, and the following conclusions are obtained:

(1) The valve is an on-off switching solenoid valve. Electromagnetic force and hydraulic force together affect the position of the valve spool. The change in the position of the valve spool will affect the brake fluid flow into the brake wheel cylinder. Based on this, the state equation is established. Then, the position of the valve spool is calculated by the square root volume Kalman filter algorithm.

(2) The electromagnetic force can be effectively adjusted by changing the coil current of the valve. The sliding mode variable structure algorithm is used to adjust the position of the valve spool, so as to change the brake fluid flow into the wheel cylinder. Finally, the purpose of accurately adjusting the brake wheel cylinder pressure was achieved.

\section{Data Availability}

The data used to support the findings of this study are available from the corresponding author upon request.

\section{Conflicts of Interest}

The authors declare that they have no conflicts of interest.

\section{References}

[1] Y. Zheng, "Research on efficient regenerative braking and anti-lock brake control for electric-wheel vehicle," Master's thesis, Jilin University, Changchun, China, 2016.

[2] J. Li-qiang, Z. Sun, and Y. Zheng, "Coordinated anti-lock braking control of compound regenerative braking system in electric-wheel vehicle," Journal of Jilin University (Engineering and Technology Edition), vol. 47, no. 5, pp. 1344-1352, 2017.

[3] J. Li-qiang, Z. X. Sun, and Y. Zheng, "A research on regenerative braking energy recovery of electric-wheel vehicle based on fuzzy control," Automotive Engineering, vol. 39, no. 10, pp. 1101-1109, 2017.

[4] S. Cheng, L. Li, H. Q. Guo, Z. G. Chen, and P. Song, "Longitudinal collision avoidance and lateral stability adaptive control system based on MPC of autonomous vehicles," IEEE Transactions on Intelligent Transportation Systems, vol. 2019, pp. 1-10, 2019.

[5] S. Cheng, L. Li, M. M. Mei, Y.-L. Nie, and L. Zhao, "Multipleobjective adaptive cruise control system integrated with DYC," IEEE Transactions on Vehicular Technology, vol. 68, no. 5, pp. 4550-4559, 2019.

[6] Z. Yu, "Review on hydraulic pressure control of electro-hydraulic brake system," Journal of Mechanical Engineering, vol. 53, no. 14, pp. 1-15, 2017.

[7] W. Han, X. Lu, and Z. Yu, "Interconnected pressure estimation and double closed-loop cascade control for an integrated electro-hydraulic brake system," IEEE/ASME Transactions On Mechatronics, vol. 2020, 2020.

[8] Z. Qu, "Research on electro-hydraulic braking control system of iveco off-road vehicle on road," Master thesis, Jilin University, Changchun, China, 2005.

[9] N. D'alfio, A. Morgando, and A. Sorniotti, "Electro-hydraulic brake systems: design and test through hardware-in-the-loop simulation," Vehicle System Dynamics, vol. 44, pp. 378-392, 2006.

[10] L. Petruccelli, M. Velardocchia, and A. Sorniotti, "Electrohydraulic braking system modelling and simulation," Brake Colloquium \& Exhibition, vol. 2003, 2003.

[11] N. Pan, L. Yu, Z. Wang et al., "Design, modeling and simulation of a new compact electro-hydraulic brake system," SAE International, vol. 2014, pp. 2014-2535, 2014.

[12] V. Milanes, "Electro-hydraulic braking system for autonomous vehicles," International Journal of Automotive Technology, vol. 11, pp. 89-95, 2010.

[13] W. Han, X. Lu, and Z. Yu, "Braking pressure control in electro-hydraulic brake system based on pressure estimation with nonlinearities and uncertainties," Mechanical Systems and Signal Processing, vol. 131, pp. 703-727, 2019.

[14] F. Tao, "The simulation and analysis of vehicle controllable braking system," Master thesis, Nanjing University of Aeronautics and Astronautics, Nanjing, China, 2010.

[15] W. Wang, "High speed on-off solenoid valve with proportional control based on high frequency PWM control," Qinghua Daxue Xuebao/Journal of Tsinghua University, vol. 51, pp. 715-719, 2011.

[16] O. U. Yang, "Passenger car research on controlling and estimating algorithm for wheel cylinder pressure of stability control system on car," Doctor thesis, Jilin University, Changchun, China, 2011.

[17] E. Nakamura, M. Soga, A. Sakai et al., Development of Electronically Controlled Brake System For Hybrid Vehicle, SAE International, Warrendale, PA, USA, 2002.

[18] I. Arasaratnam and S. Haykin, "Cubature kalman filters," IEEE Transactions on Automatic Control, vol. 54, no. 6, pp. 1254-1269, 2009.

[19] S. Cheng, L. Li, and J. Chen, "Fusion algorithm design based on adaptive SCKF and integral correction for side-slip angle observation," IEEE Transactions on Industrial Electronics, vol. 65, no. 7, pp. 5754-5763, 2018.

[20] W. Wang, J. Song, L. Yu, Y. Cheng, and Z. Xu, "Research of pressure limiting valve in the ESP under control of highfrequency PWM," Electric Information and Control Engineering, vol. 6, pp. 5225-5229, 2011.

[21] A. Meng, Research on the Precise Pressure Control of Hydraulic Actuator of Electronic Stability Control System, Tsinghua University, Beijing, China, 2014.

[22] W. Wang, Dynamics Analysis on Electronic Stability Control System Hydraulic Control Unit and Establishing an Integrated Simulation Platform, Tsinghua University, Beijing, China, 2011.

[23] L. Xue, J. Song, and H. Wang, Influence of Hydraulic ABS Parameters on Response Time and Braking Effect, SAE International, Warrendale, PA, USA, 2005.

[24] J. Yang, W. Lee, and I. Hwang, A Model-Based Design Analysis of Hydraulic Braking System, SAE International, Warrendale, PA, USA, 2003.

[25] C. Liang and D. Zhao, "Modeling and dynamic characteristics simulation for fast-switching solenoid valves in electro-hydraulic braking systems," Automotive Engineering, vol. 39, no. 1, pp. 61-66, 2017. 
[26] A. T. Zanten, "Bosch ESP systems: 5 years of experience," in Proceedings of the SAE 2000 Automotive Dynamics \& Stability ConferenceSAE International, Troy, MI, USA, 2000.

[27] C. Tu Haink, B. Rannow Michael, M. Wang et al., "Modeling and validation of a high speed rotary PWM on/off valve," in Proceedings of the ASME Dynamic Systems and Control Conference, American Society of Mechanical Engineers, Hollywood, CA, USA, pp. 629-636, October 2009.

[28] F. Meng, H. Zhang, D. Cao, and H. Chen, "System modeling and pressure control of a clutch actuator for heavy-duty automatic transmission systems," IEEE Transactions on Vehicular Technology, vol. 65, p. 7, 2016. 